\title{
Entre o ideal e o possível: experiências iniciais das obstetrizes no Sistema Único de Saúde de São Paulo'
}

\section{Between the ideal and the possible: initial experiences of midwives in the Unified Health System of São Paulo}

\section{Cláudia Medeiros de Castro}

Escola de Artes, Ciências e Humanidades. Universidade de São Paulo. São Paulo, SP, Brasil.

E-mail: claudia.medeirosळusp.br

\section{Nádia Zanon Narchi}

Escola de Artes, Ciências e Humanidades. Universidade de São Paulo. São Paulo, SP, Brasil.

E-mail: nzn®usp.br

\section{Gisele Almeida Lopes}

Escola de Artes, Ciências e Humanidades. Universidade de São Paulo. São Paulo, SP, Brasil.

E-mail: gi-alळhotmail.com

\section{Cibele Monteiro Macedo}

Escola de Artes, Ciências e Humanidades. Universidade de São Paulo. São Paulo, SP, Brasil.

E-mail: cib.mmacedoळhotmail.com

\section{Alessandra Coutinho Souza}

Escola de Artes, Ciências e Humanidades. Universidade de São Paulo. São Paulo, SP, Brasil.

E-mail: alessandra.coutinho.souza®usp.br

\section{Correspondência}

Cláudia Medeiros de Castro

Av. Arlindo Bettio, 1000, Vila Guaraciaba.

São Paulo, SP, Brasil. CEP 03828-000.

\section{Resumo}

Levando em conta a recente inserção de Obstetrizes formadas pelo Curso de Obstetrícia da Escola de Artes, Ciências e Humanidades da Universidade de São Paulo no Sistema Único de Saúde, esta pesquisa teve como propósito analisar como se deu a inserção dessas profissionais nos serviços públicos de saúde. Para isso, foi realizada pesquisa de campo, descritiva e de natureza qualitativa. Os sujeitos da pesquisa compreenderam oito egressas do Curso de Obstetrícia que estivessem trabalhando no ano de $2014 \mathrm{em}$ instituições estaduais ou municipais que fazem parte do Sistema Único de Saúde (SUS) de São Paulo. A coleta de informações ocorreu por meio de entrevista semiestruturada com questões norteadoras acerca das experiências vivenciadas pelas Obstetrizes em seu trabalho no SUS. A análise possibilitou o delineamento de quatro categorias temáticas: As obstretrizes nos hospitais: estranhamento por não saber o que é; Práticas e desafios na inserção das Obstetrizes no SUS; Entre o ideal e o possível: o cotidiano de trabalho no SUS; A repercussão do trabalho das Obstetrizes entre as usuárias. Os relatos mostram que são vários os desafios enfrentados no cenário da atenção obstétrica nos hospitais públicos, não só pelas Obstetrizes como também para os demais profissionais de saúde e, principalmente, pelas mulheres e bebês, e indicam que as pequenas mudanças ocorridas no cotidiano do trabalho só são possíveis porque são realizadas coletivamente e contribuem para o fortalecimento do SUS. Palavras-chave: Recursos Humanos em Saúde; Exercício Profissional; Obstetrizes; Sistema Único de Saúde.

Fonte financiadora: Iniciação Científica e Aprender com Cultura e Extensão da Universidade de São Paulo. 


\section{Abstract}

Considering the recent public system marketplace insertion of Midwives graduates by the Direct-entry Midwifery Program of the School of Arts, Sciences and Humanities of University of São Paulo, this study aimed to analyze how the inclusion of these professionals in public health services happened. In this sense, a descriptive and qualitative research was conducted in 2014. The study participants comprised eight graduates of Direct-entry Midwifery Program who were working in public health hospitals that are part of the Unified Health System of São Paulo, Brazil. Data collection occurred through semi-structured interview with guiding questions about the experiences of the Midwives in their work in the health institutions. The analysis enabled the design of four thematic categories: The Midwives in hospitals: estrangement not to know what it is; Practices and challenges in integration of Midwives in the Unified Health System; Between the ideal and the possible: the daily work in the Unified Health System; The effect of Midwives work among women. The reports show that there are several challenges facing the midwifery setting in public hospitals, not only for Midwives as well as for other health professionals, and especially for women and babies, which indicates that small changes in the routine work is only possible because it are held collectively and contribute to the strengthening of the Unified Health System.

Keywords: Health Manpower; Professional Practice; Midwives; Unified Health System.

\section{Introdução}

A Organização Mundial da Saúde (OMS) considera que Obstetrizes são profissionais de saúde que, quando formadas ${ }^{2}$ e capacitadas de acordo com as evidências científicas, podem atender a cerca de 87\% das necessidades de assistência obstétrica da população, o que, aliado à garantia de assistência médica e de enfermagem qualificada e à disponibilidade de serviços equipados para a assistência às emergências obstétricas, resultará em diminuição da morbidade e mortalidade materna e perinatal por causas evitáveis (WHO, 2001; 2004).

A OMS e o Fundo de Populações das Nações Unidas (UNFPA), com apoio de diversas outras entidades internacionais como a Organização dos Estados Americanos (OEA) e o Fundo das Nações Unidas para a Infância (Unicef), recomendam que os países incentivem a formação e qualificação das Obstetrizes como uma estratégia para a melhoria da atenção à saúde das mulheres por meio do desenvolvimento de programas e políticas que promovam o acesso ao planejamento reprodutivo e ao atendimento de qualidade durante o pré-natal, parto e pós-parto (OEA, 2006; UNFPA, 2006; 2007; Unicef, 2014; WHO, 2001; 2004).

Pesquisa realizada pela Universidade de Oxford (OEA, 2006) mostrou que nenhum país conseguiu reduzir a morbimortalidade materna e perinatal sem investir na capacidade de Obstetrizes em trabalhar na atenção primária ou comunitária, ou seja, na promoção da atenção à mulher e família durante todo o ciclo gravídico-puerperal, o que inclui o parto em locais como o domicílio, as casas de parto e os centros de parto normal intra-hospitalares.

Em vários países, como Austrália, Canadá, Estados Unidos, Nova Zelândia, Holanda, França e todo o Reino Unido, e até mesmo Irã e Líbano, existem diferentes combinações entre os modelos de assistência obstétrica, alguns promovidos unicamente por obstetrizes, outros por equipes integradas por obstetrizes, médicos e enfermeiros. No Canadá e Países Baixos, por exemplo, a assistência prestada por essas profissionais é dirigida ao cuidado de mu-

\footnotetext{
2 Como se trata de uma profissão em que predominam as mulheres, utilizaremos obstetriz como substantivo feminino, embora tenhamos também obstetrizes homens.
} 
lheres sem complicações durante a gravidez e parto, enquanto em outros países, como os do Reino Unido, a França, a Austrália e a Nova Zelândia, a assistência se estende para as mulheres com complicações médicas e obstétricas e é realizada em colaboração com Médicos Obstetras (Hatem et al., 2008). Na Holanda, as obstetrizes trabalham integradas ao sistema de saúde atendendo o pré-natal, o parto e o pós-parto de baixo risco, em hospitais e em domicílios. Lá, 35\% dos partos são domiciliares e as taxas de cesárea são menores que 10\% (Villa, 1999). Em todos os países do Reino Unido, as mulheres têm suas gestações, partos e pós-partos acompanhados pelas obstetrizes do National Health Service (NHS), que realizam também os primeiros cuidados com os recém-nascidos (Nice, 2007).

Obstetrizes são, assim, profissionais que promovem continuidade de cuidado para todas as mulheres de uma determinada área, agindo como líder da assistência para as gestações e partos de baixo risco e fornecendo atenção contínua para aquelas mulheres que apresentam complicações médicas ou obstétricas, em parceria com outros profissionais. Todas as evidências mostram que modelos de assistência envolvendo essas profissionais associam-se a menores taxas de intervenções realizadas sem base científica, em maior satisfação da mulher e em maior chance de aleitamento. Nos países em que a atuação de Obstetrizes é mais efetiva, os indicadores de saúde da mulher e do recém-nascido são melhores, haja vista sua importância na promoção da saúde e no cuidado das mulheres (UNFPA, 2006; 2007; 2014; WHO, 2004; 2011).

No Brasil, a assistência obstétrica atual tem sido majoritariamente oferecida por médicos especialistas em ginecologia e obstetrícia, e por enfermeiras especialistas em obstetrícia. Recentemente, o país passou a contar com obstetrizes formadas em graduação de entrada direta, o curso de Obstetrícia oferecido pela Escola de Artes, Ciências e Humanidades da Universidade de São Paulo (EACH-USP) desde o ano de 2005. Vale assinalar que tal formação existiu no Brasil de 1832 até 1971, ano em que o último curso, o da Faculdade de Medicina da USP, foi descontinuado.

Destoando das recomendações da OMS, a assistência obstétrica oferecida no Brasil, claramente centrada na figura do médico, tem sido marcada por contradições: por um lado temos razoável cobertura pré-natal, com $62 \%$ das mães de recém-nascidos vivos tendo realizado pelo menos sete consultas pré-natal ${ }^{3}$, e temos garantia de acesso ao parto hospitalar, pois $98 \%$ dos partos do país ocorrem nestas instituições. Por outro lado, há excesso de intervenções, a assistência é provida por profissionais com formação biomédica e desatualizada e os serviços são inadequados para atendimento às emergências obstétricas e neonatais, o que tem contribuído para a morbidade e a manutenção de altos índices de mortalidade materna e neonatal precoce ${ }^{4}$ (Brasil, 2004).

A alta taxa de cirurgia cesariana no país é um exemplo da prática obstétrica intervencionista vigente: enquanto a Organização Mundial da Saúde recomenda taxa de cesárea em torno de 15\% (WHO, 2015), o Brasil alcançou em 2014 uma porcentagem geral de $57 \%$ de partos cesarianos, índice que chega a mais de $84 \%$ na rede privada de saúde, razão pela qual o país ostenta o vergonhoso título de campeão mundial de cesáreas (Leal; Gama, 2015).

Quando as mulheres conseguem que o parto seja normal, há intervenções rotineiras como o uso de ocitocina sintética para acelerar o trabalho de parto, bem como as lavagens intestinais, a raspagem dos pelos pubianos e a prática rotineira da episiotomia, prática controversa usada para evitar lacerações do períneo (Leal; Gama, 2015), que nos parece uma das mais claras manifestações da ideia de que o corpo da mulher não está apto para parir e que, portanto, necessita da correção proporcionada pela medicina.

Soma-se ao excesso de intervenções e suas consequências sobre a saúde da mulher e dos bebês, a violência obstétrica, foco de atenção do Ministério Público Federal na defesa das mulheres e descrita em alguns estudos. Dentre estes, se destaca uma pesquisa mostrando que $25 \%$ das mulheres que

3 Dados sobre pré-natal e cesarianas do banco SINASC, disponíveis em www.datasus.gov.br, acesso em 4 de março de 2016.

4 O Brasil conseguiu diminuir a mortalidade infantil, porém o componente neonatal ainda se mantém em patamar alto, de 8,1 óbitos de

bebês de um a seis dias de idade por mil nascidos vivos no ano de 2011. Fonte: www.datasus.gov.br, acesso em 8 de março de 2016. 
tiveram filhos de parto natural na rede pública ou privada sofreram algum tipo de violência ao serem atendidas durante o trabalho de parto e parto (Fundação Perseu Abramo, 2010). Além disso, o desrespeito a direitos já conquistados, como a da presença do acompanhante, que é assegurado em Lei de abrangência Nacional ( $n^{\circ} .11 .634$ de 2007) e em Leis Estaduais, é demonstrado em estudos como a Pesquisa Nacional de Demografia e Saúde (PNDS) de 2006 e a pesquisa Nascer no Brasil de 2014, que respectivamente indicaram índices de apenas $16 \%$ e $20 \%$ de mulheres que puderam contar com acompanhante no processo de parto e nascimento (Leal; Gama, 2015).

Em décadas recentes, grupos organizados de mulheres e profissionais de saúde têm buscado enfrentar o modelo hegemônico de assistência obstétrica por meio de iniciativas que conformam o chamado movimento de humanização do parto (Diniz, 2005), já incorporado pelo Ministério da Saúde (MS) em documentos que tratam das ações sobre atenção obstétrica, como o Programa de Humanização no Pré-Natal e Nascimento (PHPN) de 2000 (Brasil, 200o), o Pacto Nacional pela Redução da Mortalidade Materna e Neonatal de 2004 (Brasil, 2004), e a estratégia Rede Cegonha de 2011 (Brasil, 2011). Há que se salientar também a regulamentação dos Centros de Parto Normal (CPN), que cria condições para que o parto possa ser realizado fora do ambiente dos tradicionais centros obstétricos e assistido por enfermeiras obstetras e por obstetrizes (Brasil, 2015).

A necessidade de investimento em formação profissional voltada para a assistência obstétrica humanizada, baseada em evidências científicas, como preconizado pela OMS, e que possa contribuir para a mudança no cenário da atenção obstétrica levou a discussões sobre a estrutura curricular dos cursos vigentes e a propostas de mudanças, o que ensejou possibilidades para a criação do Curso de Obstetrícia da USP e a consequente formação de obstetrizes, bem como a criação das Residências em Enfermagem Obstétrica, a melhor qualificação de enfermeiras obstetras, entre outros.

Consideramos importante dizer que a obstetriz formada pela EACH-USP tem como princípio a humanização, sem a centralidade do modelo biomédico. Com base nesse paradigma, o parto é entendido e abordado como fenômeno fisiológico que ocorre no corpo a mulher, cujas dimensões sociais, culturais e emocionais devem ser conhecidas, valorizadas e defendidas. Nesse contexto, é natural entender que a proposta formativa se baseia na garantia do protagonismo e dos direitos da mulher (Narchi; Silva; Gualda, 2012; Gualda; Narchi; Campos, 2013).

Todos os que se envolveram no projeto do curso de Obstetrícia, desde os docentes e alunos/as até outros profissionais de saúde e os movimentos organizados de mulheres, esperavam que as obstetrizes fossem atender a uma demanda da saúde pública brasileira, como é a atenção obstétrica humanizada e baseada em evidências científicas, o que, consequentemente, as faria ser absorvidas pelos serviços de saúde. Porém, as primeiras egressas do curso de Obstetrícia encontraram dificuldades para ingressar na rede de atenção obstétrica, tanto na rede privada quanto na rede pública, por força dos obstáculos impostos pelo órgão regulamentador da profissão (Conselho de Enfermagem) ${ }^{5}$ e por não haver conhecimento de que a profissão de Obstetriz pudesse ainda existir (Gualda; Narchi; Campos, 2013; Narchi; Silva, 2014).

Somente em 2012, quatro anos após a formação da primeira turma, é que começou a ocorrer melhora na absorção das Obstetrizes pelas instituições de saúde. Depois de um longo processo de negociações e impugnação de editais, a Secretaria de Estado da Saúde de São Paulo elaborou um parecer jurídico ${ }^{6}$ afirmando a legalidade da inclusão das Obstetrizes nos concursos para os hospitais da administração direita estadual. Tal parecer possibilitou que fosse realizado o primeiro concurso público no qual

\footnotetext{
5 Liminares garantiram o registro profissional das obstetrizes junto aos órgãos regulamentadores da profissão. A mobilização das docentes, egressas e da Associação de Obstetrizes da USP (AO-USP) contribuiu para que o Ministério Público Federal propusesse uma ação civil pública contra o Conselho de Enfermagem em que afirmava a legalidade da profissão com base na Lei 7478/86. Em 2015 foi dada sentença favorável às obstetrizes (Ministério Público Federal, processo nº 0021244-76.2012.403.610o) e em 2016 o processo foi encerrado.

6 Secretaria de Estado da Saúde de São Paulo. Parecer jurídico no 1011/2012, 25/o7/2012.
} 
poderiam ser inscritos portadores do "diploma de Obstetriz”. Dessa maneira, com a aprovação nesse concurso, as Obstetrizes ocuparam cargos no Sistema Único de Saúde de São Paulo (SUS-SP).

Recentes resoluções do Conselho Federal de Enfermagem (Cofen, 2015a e 2015b) somadas às diversas diretrizes do Ministério da Saúde (Brasil, 2015), abrem caminhos para que o sistema de saúde brasileiro avance e inclua as enfermeiras obstetras e as obstetrizes de forma efetiva na assistência às mulheres e famílias durante a gestação, o parto e o pós-parto, tanto no sistema público de saúde quanto no privado. Criam-se, dessa forma, oportunidades para que as obstetrizes possam participar de forma segura e efetiva do SUS, implementando os princípios da humanização e da integralidade, e dando sua contribuição para a melhoria da qualidade assistencial.

Resta-nos conhecer as experiências vivenciadas pelas obstetrizes formadas pela USP durante sua inserção na rede pública de saúde, o que justifica a realização da presente investigação. Acreditamos na necessidade da inserção das obstetrizes no SUS, não como a defesa de fatia do mercado para um grupo específico de profissionais, mas como um marcador de mudança do modelo de assistência obstétrica e como um estímulo à transformação de serviços e de outros profissionais de saúde.

\section{Método}

Realizamos pesquisa de campo descritiva e qualitativa com oito obstetrizes que trabalhavam em hospitais com leitos SUS do estado de São Paulo, três deles da administração direta estadual, localizados nos municípios de São Paulo, Ferraz de Vasconcelos e Caieiras; dois hospitais municipais administrados por Organizações Sociais de Saúde (OSS) e situados nos municípios de Arujá e São José dos Campos; e um hospital filantrópico localizado em Caraguatatuba. Apenas as obstetrizes dos hospitais estaduais haviam sido contratadas por meio de concurso público, as demais foram admitidas depois de passarem por processo seletivo específico de cada instituição.

A coleta de dados se deu por meio de entrevistas, que foram realizadas durante o ano de 2014 por três alunas do curso de Obstetrícia, uma com bolsa de extensão e duas alunas da iniciação científica. As entrevistas, previamente agendadas com as obstetrizes, ocorreram fora dos ambientes de trabalho e tiveram a duração média de uma hora.

Após obtenção do Termo de Consentimento Livre e Esclarecido, as Obstetrizes responderam um roteiro semiestruturado que comportava questões sobre os motivos da escolha pelo hospital público, as impressões pessoais sobre sua inserção na equipe de assistência obstétrica, a repercussão do seu trabalho junto à equipe de saúde, as impressões pessoais a respeito tanto das práticas obstétricas quanto da repercussão de seu trabalho junto aos demais profissionais de saúde e as usuárias do serviço de saúde. As entrevistas foram gravadas e posteriormente transcritas.

A análise dos relatos foi realizada com base em proposta metodológica de Spink (1999). A leitura e releitura das entrevistas possibilitou a organização de categorias temáticas não hierarquizadas.

\section{Resultados e discussão}

O delineamento de temas tornou possível organizar quatro categorias, que são apresentadas a seguir. Os nomes das participantes foram substituídos por expressões que caracterizam as narrativas das entrevistadas.

\section{As obstretrizes nos hospitais: estranhamento por não saber o que é}

Todas as Obstetrizes entrevistadas relataram que foram bem recebidas pela equipe que já trabalhava no local e que, no entanto, enfrentaram o estranhamento gerado pelo desconhecimento da profissão. Conforme descrito, o pouco tempo de retomada do curso, aliado à centralidade do médico na assistência obstétrica, influencia para que a profissão ainda seja pouco conhecida, o que gera alguns desconfortos nas equipes de saúde. Uma das entrevistadas salienta que os médicos estrangeiros demonstraram maior conhecimento da profissão, o que revela como no Brasil a assistência é distante das recomendações internacionais que enfatizam a importância do compartilhamento do trabalho com as obstetrizes na assistência obstétrica: 
Quando eu entrei lá, como em todo lugar, o pessoal não tinha conhecimento da formação de Obstetriz. Quando nós entramos foram quatro obstetrizes que entraram juntas, o pessoal não tinha conhecimento... (Perseverança)

temos que explicar que temos as mesmas competências da enfermeira obstétrica, que nosso curso é voltado para a saúde da mulher e que não podemos trabalhar em setores como clínica médica (Esperança)

Então, primeiro que, em geral, em todos os hospitais que eu trabalhei, a princípio eles não conhecem a sua formação. Exceto os médicos estrangeiros. os médicos estrangeiros aceitam a gente melhor porque eles estão acostumados com as obstetrizes. Mas os [médicos] do Brasil não. Então é muito difícil, assim, até que eles conhecem e entendam qual é a sua formação (Empoderamento)

Depois de três semanas que eu estava trabalhando lá, acho que perceberam que eu era obstetriz e quiseram me mandar embora. Fizeram uma reunião com toda a equipe e os médicos disseram que eu poderia ficar porque era esforçada... (Resistência)

Com o desconhecimento da formação e da profissão, alguns questionamentos foram levantados pela própria equipe em relação às competências profissionais das obstetrizes:

Eperguntavam 'aho que é? Que cursoéesse? Desde quando existe?' $E$ levantaram várias dúvidas, 'ah vocês podem fazer o administrativo? Vocês tiveram isso? Tiveram aquilo?'(..) a meu ver, houve só o estranhamento por não saber o que é (Perseverança)

Minha chefe me dizia que o... [OSS] não contrata Obstetrizes por não confiar no profissional... eles consideram que a Obstetriz não é apta a exercer as funções do projeto Parto Seguro (Resistência)

Acho até que, antes de entrar no mercado de trabaIho, a obstetriz tem aquela visão de 'ah, não estou preparada, e agora?!' e não é bem assim. Quando a gente ingressa no mercado e se depara com a roti- na e com as dificuldades, a gente vê que estamos muito bem preparadas, a gente vê que sabemos mais até que muitos outros profissionais da saúde. Quando eu entrei, alguns profissionais falavam que obstetriz só pode trabalhar sob a gerência de uma enfermeira obstétrica e quanto a isso fui bem dura, expliquei que tinha as mesmas competências em obstetrícia que qualquer enfermeira obstétrica, que eu tinha registro..., depois disso acho que fui muito mais respeitada (Continência)

A profissão da obstetriz é regulamentada pela mesma Lei que regulamenta o exercício profissional da Enfermagem que tem a versão mais recente datada de 1986 (Brasil, 1986). Há ainda que se destacar que, no estado de São Paulo, a partir do parecer jurídico da SES-SP, foi determinado que os concursos públicos não podem fazer diferenciação entre enfermeiras com especialização em obstetrícia e obstetrizes, com pena de haver discriminação ilegal da profissão. Entretanto, há um caminho a ser percorrido para que os dispositivos legais que oferecem garantias para que o exercício profissional das obstetrizes possa ser incorporado no cotidiano do trabalho.

\section{Práticas e desafios na inserção das obstetrizes no sus}

O excesso de intervenções que marca o atual cenário da assistência obstétrica resultou na medicalização do parto e tornou rotineiras práticas que devem ser realizadas com cautela ou que devem ser abolidas (Diniz, 2005). Quando entra na cena do parto, a obstetriz, que tem formação voltada para a assistência humanizada e baseada em evidências científicas, atos rotineiros como a episiotomia e o uso indiscriminado da ocitocina sintética, entre outros procedimentos, são questionados pelas obstetrizes, o que gera questionamentos na equipe.

A episitomia pode ser tomada como exemplo de um procedimento que no Brasil é realizado rotineiramente nos hospitais, mas que tem sido discutido em estudos e denunciado por muitas mulheres como uma mutilação genital. A preocupação com a realização indiscriminada do procedimento levou a Secretaria Municipal de Saúde de São Paulo a mo- 
nitorar suas taxas, e o Ministério Público a realizar audiência pública no ano de 2014 sobre o tema. Esse é um exemplo de como é evidente o descompasso entre as evidências científicas, as reivindicações das mulheres e as práticas adotadas nos hospitais, o que resultou no fato de uma das obstetrizes deste estudo ter sido chamada para explicar a sua superiora por que não realizava o procedimento.

As resistências são geradas com a desconstrução das práticas atuais e também com a adoção de posturas que valorizam o protagonismo da mulher e do bebê na cena do parto (Gonçalves; Brigagão, 2014), o que, em nosso entendimento, leva a redimensionar as relações de poder:

estranham porque o jeito que a gente conduz o trabalho de parto, sem muita intervenção, sem ocitocina, não rompemos bolsa com pouco dilatação. $\varepsilon$ aí perguntam 'porque vocês não fazem isso?' $\varepsilon$ ficam um pouco desconfiadas. 'Por que vocês não fazem episiotomia? (Perseverança)

... esses dias minha chefia me chamou pra perguntar por que eu não faço episio, porque eles foram ver os indicadores e viram que eu não faço episio, $e$ aí eu tive que explicar o porquê e ela ficou me questionando, falando que as mulheres estavam reclamando de edema, tipo assim, 'eu tenho que fazer episio pra prevenir edema de períneo' não faz sentido (Mudança)

Eu consegui assistir alguns partos em que a mulher ficava em outras posições que não fosse a deitada, mas a grande maioria era deitada mesmo, eu tentava mudar mas era bem difícil... A episiotomia eu cheguei a fazer algumas vezes, por pressão. No final, consegui argumentar bastante para não fazer (...) Minha luta também era a amamentação na primeira hora de vida. As técnicas e auxiliares já queriam fazer todos os procedimentos assim que o bebê nascia...e só depois de quarenta, cinquenta minutos é que entregavam pra mãe...não dava! (Resistência)

Em relação aos funcionários do hospital, em geral, o primeiro impacto é sempre uma surpresa, porque 'ah, ela não faz episio', 'ah, ela não gosta de levar muito cedo pra sala', 'ah, ela deixa a mãe fazer o que quer',... então no início foi um impacto bem grande... (Continência)

O modelo obstétrico é aquele que a gente conhece bem, cheio de intervenções e violência obstétrica. Láé um hospital escola, então muitas intervenções são feitas para os residentes aprenderem mesmo... a gente teve que ter muito jogo de cintura pra lidar com as situações e se manter ali... (Resiliência)

As obstetrizes entrevistadas relatam que o fato de ser obstetriz não é sinônimo de uma assistência diferenciada, pois há o risco de serem capturadas pelas práticas tradicionais, ou serem obrigadas a se adaptar ao sistema às custas da manutenção do emprego. Para que mudanças ocorram é preciso mostrar que as práticas são baseadas em evidências científicas e é necessário somar com outros profissionais que compartilham de um novo modelo de assistência obstétrica.

Nesse sentido, as entrevistadas relataram casos em que puderam contribuir para mudanças na prática de alguns profissionais, por meio da curiosidade que levantam em relação às suas condutas, que são diferentes dos demais, o que ilustra as considerações de Cecatti (2005), para quem é a atuação dos profissionais que compartilham das novas práticas que contribuirá para o melhor desfecho dos partos e para a redução de eventos graves:

eu não acho que é a obstetriz que vai fazer a diferença não, eu acho que assim, faz a diferença na medida em que você consegue conversar e mostrar evidência, mostrar um projeto novo, um trabalho novo, mas não significa também que seja só a obstetriz não. Porque tem obstetriz que não trabalha tão bem quanto a gente espera, que é intervencionista, que acha que a episio deve ser feita, que acha que tem que fazer nascer (Empoderamento)

porque, quando nós entramos lá, a maioria dos enfermeiros, que nos recepcionaram muito bem, queriam entender por que nós éramos diferentes: 'o que essa sua formação foi diferente da minha, ah mas por que você faz isso e não faz aquilo?' $\varepsilon$ aí acabou que algumas enfermeiras acabaram se 
interessando por alguns cursos, 'ah eu queria fazer um curso'... 'por quevocês não fazem episiotomia?'.. Então nessa parte houve uma mudança, em saber qual era o nosso diferencial e elas se atualizarem também com a nova prática, saber o que está mudando... (Perseverança)

quando eu cheguei lá a taxa de episiotomia era $80 \%$ dos partos normais, então quase todas as mulheres tinham episio, e aí, no primeiro mês que eu entrei, junto com as outras enfermeiras, caiu pra $40 \%$, ou seja, metade de um mês pro outro (Mudança)

Eu consegui fazer um trabalho bem bacana... a mulher se movimentar livremente, fazer agachamento, só levar pra sala de parto quando o bebê estava realmente nascendo pra evitar procedimentos desnecessários, manter a bolsa integra...havia duas enfermeiras bem legais e dispostas a receber ideias e coisas novas...eu ensinei bastante coisa e também aprendi muito... (Resistência)

... acho que a assistência da obstetriz influencia na assistência de outros profissionais, sim! Claro que não é uma coisa imediata, mas eu consigo ver muitas mudanças boas lá...por exemplo, episiotomia de rotina diminuiu muito, uso do chuveiro liberado pra todas as mulheres, uso da bola, contato pele a pele, clampeamento tardio do cordão, essas coisas... estão mudando (Continência)

Também percebo que tanto os médicos quanto as enfermeiras obstétricas tem um olhar imenso sobre mim. Muitas das coisas que eu e [outra obstetriz] fazíamos, eles começaram a fazer também, percebi que eles até começaram a ser mais atenciosos [com as mulheres], então acho que isso significa que a gente serve um pouco de exemplo também... antes não se colocava o bebê em cima da mãe logo após o nascimento, hoje isso já é mais comum lá, depois que viram a gente fazer isso... (Resiliência)

\section{Entre o ideal e o possível: o cotidiano de trabalho no SUS}

As entrevistadas relataram que há outro aspecto a ser destacado: muitas vezes intervenções desne- cessárias são realizadas devido à superlotação dos hospitais, pois há uma grande demanda assistencial que exige respostas dos profissionais, nem sempre as mais adequadas, para prestar a assistência possível. As narrativas reproduzem o discurso que justifica práticas intervencionistas para "liberar leito", ou seja, as falas são capturadas pela dinâmica institucional, que tem como resultado não dar visibilidade à necessidade, por exemplo, de que a sociedade exija maior número de profissionais de saúde e mais leitos nos locais em que estes são insuficientes. Esta é uma situação perversa que leva os profissionais a buscar lidar no plano individual com o "conflito de postura e condutas", quando a solução deve dar-se no coletivo:

a demanda lá está bem grande, então acaba que você coloca ocitocina em uma paciente, não porque... talvez não seja o momento certo mas é preciso liberar leito, tem uma outra paciente que está esperando na maca no corredor, então você fica em um conflito de posturas e de condutas, às vezes você coloca a ocitocina pra acelerar o trabalho de parto pra aquela mulher ter o leito, não é o correto né mas... (Perseverança)

aqui o ponto de dificuldade é que temos uma única obstetriz para um setor inteiro da maternidade, que é pronto atendimento, sala de parto, alojamento conjunto e tratamento de risco. É muita coisa para uma pessoa só dar conta de tudo...o que gera dificuldade no atendimento (Obstinação)

Obstetrizes relatam que trabalhando no SUS encontram muitos desafios que acabam prejudicando a assistência. Além da superlotação, fatores como a formação profissional dos muitos componentes da equipe, já citada anteriormente, e a estrutura física dos hospitais, que ainda mantém enfermarias com vários leitos nos quais as mulheres vivenciam o trabalho de parto, somada à falta de alguns insumos, também contribuem para a assistência insatisfatória. Na atenção humanizada ao parto, por exemplo, preconiza-se o uso de métodos não farmacológicos para o alívio da dor, como o banho de chuveiro; as limitações físicas encontradas nos hospitais públicos com poucos banheiros para muitas mulheres não permitem oferecer tal recurso: 
as nossas limitações estruturais também são muito difíceis, temos um chuveiro, então você tem cinco mulheres em trabalho de parto e um chuveiro, então você tem que ficar rodiziando, nós não temos cama de PPP, então é outra dificuldade que nós temos, estrutural... (Perseverança)

... acho que eu passei uns seis meses pedindo pra conseguir uma bola. A banqueta eu pedi pra comprar. A cama PPP, eu fiz um relatório falando das recomendações da OMS, do porque eu estava pedindo o material, eu e a outra enfermeira obstetra assinamos e mandamos pra chefia, e ela nem respondeu o relatório (Mudança)

Alguns hospitais, ainda que não possuam um Centro de Parto Normal, têm quartos em que a mulher permanece no trabalho de parto, no parto e no pós-parto, os chamados PPPs. Porém, há poucos profissionais disponíveis para a assistência. Devido à grande demanda de mulheres e o reduzido quadro de profissionais, o uso de estruturas, como o quarto PPP, fica prejudicado:

aqui a gente tem duas salas de PPP toda equipada, com banheira e tudo mais, mas aqui tem uma alta rotatividade de mulheres, muita gente, é um privilégio a gente ter isso aqui, mas não é sempre que usa, aqui não é Centro, Centro mesmo de Parto Normal, pra você poder deixar uma pessoa aqui (PPP) tem que ficar uma pessoa aqui, e como que eu faço com aquele pré-parto? Bombando né? $\varepsilon$ isso me deixa um pouquinho triste. (Esperança)

As entrevistadas ressaltam que para mudanças acontecerem é preciso que haja maior número de obstetrizes e de profissionais qualificados nos demais âmbitos da assistência à saúde da mulher:

O SUS precisa muito de profissionais, assim, a gente sabe que nem tudo acontece do jeito que deveria, mas eu acho que ainda deve ser mais incisivo, não só aqui ter obstetrizes, mas lá na frente, no pré-natal, no planejamento reprodutivo (Esperança)

O que se pode notar nas narrativas dessas obstetrizes, que aos poucos estão se inserindo no SUS, é a vontade de mudar a realidade que encontram e o afeto com que investem na sua profissão, que pode ser ilustrado pela seguinte frase:

Eu sou feliz com o que eu faço, talvez eu seja privilegiada por trabalhar com o que eu gosto, ainda nãoé o ideal, claro, mas aos poucos a gente vai mudando essa realidade (Esperança)

\section{A repercussão do trabalho das Obstetrizes entre as usuárias}

Em relação às usuárias e familiares, as Obstetrizes entrevistadas dizem notar grande satisfação, pois as mulheres percebem a assistência diferenciada que recebem. Para Kennedy, Rousseau e Low (2003), em um cenário altamente técnico, é a obstetriz quem consegue criar uma aliança com a mulher, o que nos parece fundamental na atenção ao processo de parto e nascimento:

a gente tende a incluir um pouco mais a família, paciência no trabalho de parto, fica mais ao lado da mulher, diferente de outros profissionais que eu vejo lá (Perseverança)

$\varepsilon$ as mulheres elogiam bastante, assim, a gente faz bastante diferença (Mudança)

acho que a gente faz muita diferença pras mulheres, elas gostam bastante, agradecem muito (...) está vindo de toda gente, gente de Poá que não tem maternidade, Ferraz, Suzano, Santa Isabel, Mogi, outro dia tinha uma moça de Arujá, então acho que o boca a boca tá fazendo muita diferença, ninguém vem pra um hospital que as pessoas dizem ser ruim, então acho que a gente está impactando positivamente sim (Esperança)

Com as pacientes eu vejo que o atendimento é diferenciado e elas agradecem muito. Um dia atendi uma gestante adolescente, tinha quinze anos, depois a mãe dela agradeceu muito. Na semana seguinte ela voltou com a irmã dessa menina e eu também atendi, senti que ela ficou muito aliviada por ser eu quem estava atendendo, então eu vejo que elas gostam bastante do atendimento (Continência) 


\section{Considerações finais}

As Obstetrizes que passam a integrar os quadros dos hospitais de São Paulo podem contribuir para adoção de um novo modelo de assistência obstétrica. Conforme exposto, sua inserção nas equipes é recente e seu número mínimo, mas as narrativas indicam que as mudanças são perceptíveis nos locais de trabalho. Trata-se, ainda, de um ganho para o SUS-SP o ingresso de uma nova profissão no quadro da saúde via concurso público. Consideramos necessário que o processo de inserção das obstetrizes nos hospitais públicos seja acompanhado da reflexão sobre o SUS como importante conquista social, sobre o direito de acesso universal à saúde e o direito de assistência integral e humanizada para que, assim, possam enfrentar as dificuldades históricas dos serviços públicos de saúde, como a superlotação, a infraestrutura precária e a falta de profissionais. É preciso ainda considerar que, no estado de São Paulo, boa parte dos hospitais estaduais estão sob administração de Organizações Sociais de Saúde, enquanto muitos hospitais da administração direta lutam para sobreviver ao que parece ser um sucateamento proposital, uma vez que o estado tem sido um expoente da adoção do modelo das Organizações Sociais (Pilotto, 2015), o que reflete nos serviços de atenção obstétrica.

Conforme exposto, assim como em outros países, a efetiva inserção das obstetrizes no SUS pode contribuir para melhorar o cenário da atenção à saúde da mulher no Brasil (Narchi; Cruz; Gonçalves, 2013). É necessário superar o estranhamento inicial provocado pela nova profissão, bem como pela adoção de práticas que incentivam o protagonismo da mulher e do bebê no parto e nascimento. É necessário que obstetrizes, apoiadas nas políticas públicas para assistência obstétrica no Brasil, possam somar-se a outros profissionais que concebem o parto como um evento fisiológico, cujas dimensões sociais e emocionais ultrapassam as biológicas. Esse é um evento que pode ser potencializado como experiência positiva quando a família e a comunidade são também consideradas como elementos importantes para uma boa assistência.

Os relatos das entrevistadas mostram que são vários os desafios enfrentados no cenário da atenção obstétrica nos hospitais públicos, não só pelas obstetrizes como também para os demais profissionais de saúde e, principalmente, pelas mulheres e bebês, e indicam que as pequenas mudanças ocorridas no cotidiano do trabalho só são possíveis porque são realizadas coletivamente e contribuem para o fortalecimento do SUS.

\section{Referências}

BRASIL. Lei n ${ }^{0} 7 \cdot 498$, de 25 de junho de 1986. Dispõe sobre a regulamentação do exercício da enfermagem e dá outras providências. Diário Oficial [da] República Federativa do Brasil, Brasília, DF, 26 jun. 1986.

BRASIL. Ministério da Saúde. Portaria GM no 569, de $1^{0}$ de junho de 20oo. Institui o Programa de Humanização no Pré-natal e Nascimento, no âmbito do Sistema Único de Saúde. Diário Oficial [da] República Federativa do Brasil, Brasília, DF, 8 jun. 200o. Seção 1, p. 4. Disponível em: <http://bit. ly/2isxhoa>. Acesso em: 13 jan. 2017.

BRASIL. Ministério da Saúde. Pacto nacional pela redução da mortalidade materna e neonatal. Brasília, DF, 2004. Disponível em: <http://bit. ly/2jrUQM8>. Acesso em: 13 jan. 2017.

BRASIL. Ministério da Saúde. Portaria n ${ }^{0}$ 1.459, de 24 de junho de 2011. Institui no Sistema Único de Saúde a Rede Cegonha. Diário Oficial [da] República Federativa do Brasil, Brasília, DF, 27 jun. 2011. Seção 1, p. 109. Disponível em: <http:// bit.ly/2fEmUwq>. Acesso em: 13 jan. 2017.

BRASIL. Ministério da Saúde. Gabinete do Ministro. Portaria $\mathrm{n}^{0} 11$, de 7 de janeiro de 2015. Redefine as diretrizes para implantação e habilitação de Centro de Parto Normal (CPN), no âmbito do Sistema Único de Saúde (SUS), para o atendimento à mulher e ao recémnascido no momento do parto e nascimento, em conformidade com o Componente Parto e Nascimento da Rede Cegonha, e dispõe sobre os respectivos incentivos financeiros de investimento, custeio e custeio mensal. Diário Oficial [da] República Federativa do Brasil, Brasília, DF, 7 jan. 2015. Disponível em: <http:// bit.ly/2jMUkfc $>$. Acesso em: 13 jan. 2017. 
CECATTI, J. G. Saúde da mulher: enfoque da evidência científica para a prevenção da morbidade e mortalidade materna. Revista Brasileira de Saúde Materno Infantil, Recife, v. 5, n. 1, p. 9-11, 2005.

\section{COFEN - CONSELHO FEDERAL DE}

ENFERMAGEM. Resolução 477/2015. Dispõe

sobre a atuação de enfermeiros na assistência às gestantes, parturientes e puérperas. Brasília, DF, 2015a. Disponível em: <http://bit.ly/2j8FBIl>. Acesso em: 13 jan. 2017.

\section{COFEN - CONSELHO FEDERAL DE}

ENFERMAGEM. Resolução 478/2015. Normatiza a atuação e a responsabilidade civil do Enfermeiro Obstetra e Obstetriz nos Centos de Parto Normal e/ou Casas de Parto e dá outras providências. Brasília, DF, 2015b. Disponível em: <http://bit. ly/2isY8R2>. Acesso em: 13 jan. 2017.

DINIZ, S. Humanização da assistência ao parto no Brasil: os muitos sentidos de um movimento. Ciência \& Saúde Coletiva, Rio de Janeiro, v. 10, n. 3, p. 627-637, 2005.

FUNDAÇÃO PERSEU ABRAMO. Gravidez, filhos e violência institucional no parto. In:

Mulheres brasileiras e gênero nos espaços público e privado: pesquisa de opinião pública. São Paulo: Fundação Perseu Abramo, 2010.

GONÇALVES, R.; BRIGAGÃO, J. I. M. As dimensões do cuidado e sua incorporação no ambiente do estágio curricular. Saúde em Debate, Rio de Janeiro, v. 38, n. 100, p. 181-189, 2014.

GUALDA, D. M. R.; NARCHI, Z. N.; CAMPOS, E. A. Strengthening midwifery in Brazil: education, regulation and professional association of midwives. Midwifery, New York, v. 29, n. 10, p. 1077-1081, 2013.

HATEM, M. et al. Midwife-led versus other models of care for childbearing women. Cochrane Database of Systematic Reviews, Oxford, v. 8, n. 4, 2008. Disponível em: 〈http://bit.ly/2jAU1k3〉. Acesso em: 16 jan. 2017.

KENNEDY, H. P.; ROUSSEAU, A. L.; LOW, L. K. An exploratory metasynthesis of midwifery practice in the United States. Midwifery, London, v. 19,

n. 3, p. 203-214, 2003.
LEAL, M. C.; GAMA, S. G. N. Sumário executivo temático da pesquisa. In: LEAL, M. C. (Org.). Nascer no Brasil. Rio de Janeiro: Fiocruz, 2015. p. 2-7. Disponível em: <http://bit.ly/1GsY2fG>. Acesso em: 16 jan. 2017.

NARCHI, N. Z.; CRUZ, E. F.; GONCALVES, R. O papel das obstetrizes e enfermeiras obstetras na promoção da maternidade segura no Brasil. Ciência e Saúde Coletiva, Rio de Janeiro, v. 18, n. 4, p. 1059-1068, 2013.

NARCHI, N. Z.; SILVA, L. C. F. P.; GUALDA, D. M. R. Contexto, desafios e perspectivas na formação de obstetrizes no Brasil. Saúde e Sociedade, São Paulo, v. 21, n. 2, p. 510-519, 2012.

NARCHI, N. Z.; SILVA, B. A. Marketplace insertion and professional practice of direct-entry midwives in Brazil: a descriptive study. American Journal of Health Research, New York, v. 2, p. 327-333, 2014.

NICE - NATIONAL INSTITUTE FOR HEALTH AND CLINICAL EXCELLENCE. Intrapartum care: care of healthy women and their babies during childbirth. London: Royal College of Obstetricians and Gynaecologists, 2007.

OEA - ORGANIZACIÓN DE LOS ESTADOS AMERICANOS. Acceso a servicios de salud materna desde una perspectiva de derechos humanos. Washington, DC, 2006. Disponível em: <http://bit.ly/2jPPWbp>. Acesso em: 16 jan. 2017.

PILOTTO, B. S. Gestão de saúde por organizações sociais no estado de São Paulo: avanços e limites do controle externo. 2015. Dissertação (Mestrado em Saúde Coletiva) - Universidade Federal de São Paulo, São Paulo, 2015.

SPINK, M. J. (Org.). Práticas discursivas e produção de sentidos no cotidiano: aproximações teóricas e metodológicas. São Paulo: Cortez, 1999.

UNFPA - UNITED NATIONS POPULATION FUND. Towards MDG 5: scaling up the capacity of midwives to reduce maternal mortality and morbidity: workshop report. New York: UNFPA, 20o6. Disponível em: <http://bit.ly/2jBam8y>. Acesso em: 16 jan. 2017.

UNFPA - UNITED NATIONS POPULATION FUND. Maternal mortality update 20o6. Expectation and 
delivery: investing in midwives and others with midwifery skills. New York, 2007. Disponível em: <http://bit.ly/2iy28MR>. Acesso em: 16 jan. 2017. UNFPA - UNITED NATIONS POPULATION FUND. The state of world's midwifery report: delivering health, saving lives. New York, 2014. Disponível em: <http://bit.ly/2iD5Ac2>. Acesso em: 16 jan.

2017 .

UNICEF - UNITED NATIONS CHILDREN'S FUND. Countdown to 2015 and beyond: fulfilling the health agenda for women and children: the 2014 Report. Geneva, 2014. Disponível em: <http://bit. ly/1jCI5qJ>. Acesso em: 16 jan. 2017.

VILLA, T. C. S. et al. A enfermagem no sistema local de saúde na Holanda. Revista Latino-Americana de Enfermagem, Ribeirão Preto, v. 7, n. 5, p. 127-135, 1999.
WHO - WORLD HEALTH ORGANIZATION. Safe motherhood needs assessment: guidelines. Geneva, 2001. Disponível em: <http://bit. ly/2joauv3>. Acesso em: 16 jan. 2017.

WHO - WORLD HEALTH ORGANIZATION. Making pregnancy safer: the critical role of the skilled attendant. Geneva, 2004. Disponível em: <http:// bit.ly/2jqRwDB>. Acesso em: 16 jan. 2017.

WHO - WORLD HEALTH ORGANIZATION. Every woman and child: accounting for results and progress in maternal, newborn and child health: global strategy for women's and children's health. Geneva: The Partnership for Maternal, Newborn and Child Health, 2011.

WHO - WORLD HEALTH ORGANIZATION. Statement on caesarean section rates. Geneva, 2015. Disponível em: <http://bit.ly/1RzzF1b>. Acesso em: 16 jan. 2017.

\section{Contribuição dos autores}

Castro e Narchi foram responsáveis pela análise dos dados, redação e revisão do artigo. Lopes, Macedo e Souza foram responsáveis pela coleta e análise dos dados e composição da bibliografia. 